\title{
Correction to: Update on management and progress of novel therapeutics for R/R AML: an Iberian expert panel consensus
}

\author{
Pau Montesinos ${ }^{1,2}$ (1) Juan Bergua ${ }^{3} \cdot$ Joana Infante ${ }^{4} \cdot$ Jordi Esteve $^{5} \cdot$ José Eduardo Guimaraes $^{6} \cdot$ Jordi Sierra $^{7}$. \\ Miguel Ángel Sanz ${ }^{1}$
}

Published online: 30 January 2020

(C) Springer-Verlag GmbH Germany, part of Springer Nature 2020

Correction to: Annals of Hematology

https://doi.org/10.1007/s00277-019-03820-w

After publication of this paper, the authors determined that an additional information in the funding section was missing.

Below is the complete information:

Funding information Financial support for medical editorial assistance, copyright permission and publication costs was provided by Daiichi Sankyo, Inc., a member of the Daiichi Sankyo Group. Medical writing assistance was provided by Celia Miguel-Blanco, $\mathrm{PhD}$, on behalf of Springer Healthcare.

Publisher's note Springer Nature remains neutral with regard to jurisdictional claims in published maps and institutional affiliations.

The online version of the original article can be found at https://doi.org/ 10.1007/s00277-019-03820-w

Pau Montesinos

montesinos_pau@gva.es

1 Hematology Department, Hospital Universitari I Politècnic La Fe, Av, Fernando Abril Martorell, 106, 46026 Valencia, Spain

2 CIBERONC Instituto de Salud Carlos III, Madrid, Spain

3 Division of Hematology/Oncology, Hospital San Pedro Alcántara, Cáceres, Spain

4 Serviço de Hematologia e Transplantação deMedula Óssea, Hospital de SantaMaria, Centro Hospitalar de Lisboa Norte, Lisbon, Portugal

5 Department of Hematology, IDIBAPS Hospital Clinic, Barcelona, Spain

6 Serviço de Hematologia Clínica, Centro Hospitalar Universitário de São João, Porto, Portugal

7 Hematology Department, Hospital de la Santa Creu i Sant Pau, IIB Sant Pau and Jose Carreras Leukemia Research Institutes,

Autonomous University of Barcelona, Barcelona, Spain 